(REVIEW ARTICLE)

\title{
Lead: A concise review of its toxicity, mechanism and health effect
}

\author{
Aliyu Haruna Sani * and Musa Amanabo \\ Department of Biochemistry, Faculty of Natural Sciences, Ibrahim Badamasi Babangida University Lapai, Niger State, \\ Nigeria.
}

GSC Biological and Pharmaceutical Sciences, 2021, 15(01), 055-062

Publication history: Received on 01March 2021; revised on 04 April 2021; accepted on 07 April 2021

Article DOI: https://doi.org/10.30574/gscbps.2021.15.1.0096

\begin{abstract}
Heavy metal toxicity over the years has been proven to be a source of diverse health risks. Thou these metals, play certain biological roles, they are in excess amount get accumulated in the body and food chain displaying a chronic effect in the long run. Lead toxicity is an important environmental disease and its effects on the human body are devastating with its toxicity dependent upon the absorbed dose, the route of exposure as well as the duration of exposure. There is almost no function in the human body which is not affected by lead toxicity. Lead is highly persistent in the environment and because of its continuous use, its levels rise in almost every country particularly in developing countries like Nigeria where it occupies unique physical and chemical properties that make it suitable for a large number of applications. Various public health measures have been undertaken to control, prevent and treat lead toxicity occurring at various levels, such as occupational exposure, accidents and environmental factors. This article reviews the works listed in scientific literatures with recent updates regarding the toxicity of lead. Focus is also on the biomarkers of lead toxicity on the renal, hematological and oxidative stress conditions.
\end{abstract}

Keywords: Heavy metals; Lead toxicity; Oxidative stress; Free radicals

\section{Introduction}

Heavy metals are generally referred to as those metals which possess a specific density of more than $5 \mathrm{~g} / \mathrm{cm} 3$ and adversely affect the environment and living organisms [1]. Heavy metals in low concentrations, play an integral biochemical and physiological functions like homeostasis, transport, compartmentalization and binding to required cell constituents thou when their concentrations exceed certain threshold concentrations, they become noxious [2]. Heavy metals are significant environmental pollutants and their toxicity is a problem of increasing significance for ecological, evolutionary, nutritional and environmental reasons since they are capable of permeating the surroundings via natural means and through human activities. These metals bind with protein sites which are not made for them by displacing original metals from their natural binding sites causing malfunctioning of cells and ultimately toxicity [3,4]. The main objective of this review is to provide insight into the sources of lead poisoning, their harmful effects on the environment and living organisms as well as their diagnosis and treatment strategy.

Lead is the most important toxic heavy element in the environment [5]. Its important properties like softness, malleability, ductility, poor conductibility and resistance to corrosion seem to make difficult to give up its use but as a result of its non-biodegradable, its concentration accumulates in the environment with increasing hazards [6].

\footnotetext{
${ }^{*}$ Corresponding author: Aliyu Haruna Sani

Department of Biochemistry, Faculty of Natural Sciences, Ibrahim Badamasi Babangida University Lapai, Niger State, Nigeria. 


\section{Lead exposure}

Exposure to lead arises through two primary media: air and surfaces. Absorption in general can occur through four primary routes: inhalation, ingestion, transdermal, and percutaneous [7]. Human exposure to lead and its compounds occurs mostly in lead related occupations with various sources like leaded gasoline, industrial processes such as smelting of lead and its combustion, pottery, boat building, lead based painting, lead containing pipes, battery recycling, grids, arm industry, pigments, printing of books, among others [6].

Lead painting is an integral source of lead exposure and the major source of lead toxicity in children. The deterioration of lead in paint forms airborne lead, which settles and contaminates dusts and soils [8,9]. Exposure to soil that contains particulate lead has been shown to be significantly hazardous for children, who are more commonly exposed by ingestion of house dust or soil than by paint chips [10]. Drinking water is also a major source of lead exposure. It is estimated to be responsible for approximately 20 percent of the total daily exposure experienced by the majority of the US population [11]. Lead is a common environmental pollutant. Exposure to lead could significantly be related to occupational sites, production of lead-acid batteries, or pipes, metal recycling and foundries [12]. Occupational exposure is a major source of lead poisoning in adults and the main cause of lead poisoning [13]. Working facilities, such as radiation shields, ammunition, certain surgical equipment, developing dental X-ray films prior to digital X-rays, fetal monitors, plumbing circuit boards, jet engines, ceramic glazes, lead miners and smelters, plumbers, automobile mechanics, glass manufacturers; all these increases chances of toxicity with increasing exposure [14].

\section{Toxicity of lead}

Lead is a highly poisonous metal affecting almost every organ in the body. Lead toxicity in children is of devastating consequence than in adults. Infants and young children are especially sensitive to even low levels of lead, which may contribute to behavioural problems, learning deficits and lowered intelligence quotient (IQ) [15]. In the middle and aged population, long-term exposure to lead has been reported to cause anaemia, increase in blood pressure, severe damage to the brain and kidneys. In pregnant women, high exposure to lead may cause miscarriage while chromic lead exposure in males results in infertility [16].

\section{Signs and symptoms of lead poisoning}

While time of exposure plays an important role in lead poisoning, the general signs and symptoms varies from person to person $[17,18]$. There are also studies which show no symptoms of lead poisoning even with elevated levels of lead in the body [19]. While chronic lead exposure usually manifests within weeks to months; acute symptoms and signs results from short time intense exposures [20]. Generally, signs and symptoms of chronic lead exposure include loss of short-term memory or concentration, depression, nausea, abdominal pain, loss of coordination, and numbness and tingling in the extremities, fatigue, problems with sleep, headaches, stupor, slurred speech, and anaemia [21,22].

While blood lead levels from 25 and $60 \mu \mathrm{g} / \mathrm{dL}$ results in anaemia as well as neuropsychiatric effects such as delayed reaction times, irritability, and difficulty in concentrating, as well as slowed down motor nerve conduction and headache [23]. In adults, abdominal colic, involving paroxysms of pain, may appear at blood lead levels higher than $80 \mu \mathrm{g} / \mathrm{dL}$ [17], while blood lead levels exceeding $100 \mu \mathrm{g} / \mathrm{dL}$ results in severe manifestations, like signs of encephalopathy (condition characterized by brain swelling) accompanied by increased pressure within the skull, delirium, coma, seizures, and headache [24]. Central nervous system and neuromuscular manifestations usually result from intense exposure, while gastrointestinal features usually result from exposure over longer periods [25].

\section{Detection of lead poisoning}

There are several procedures for determining the level of lead in the blood. lead poisoning is often detected by the presence of changes in blood cells visible under the microscope or deletion of dense lines in the bones of children seen on X-ray.

Although, the determination of lead in blood samples is the main tool in detecting elevated levels of body lead with the drawback being only able to detect circulating lead levels and not the amount of lead stored in the body. Blood levels of $10 \mu \mathrm{g} / \mathrm{dL}$ for adult and $5 \mu \mathrm{g} / \mathrm{dL}$ for children of the whole blood depicts lead poisoning [26]. 


\section{Mechanism of Lead Toxicity}

Lead as a ubiquitous environmental toxin capable of causing numerous acute and chronic circulatory, neurological, hematological, gastrointestinal, reproductive and immunological pathologies. Possible pathway of lead poisoning is mainly due to lead occurring mainly via the ingestion of food or water contaminated with lead. However accidental ingestion of contaminated soil, dust or lead based paint may also result in poisoning [27]. Lead primarily disrupts heme synthesis in bone marrow erythroblasts through the inhibition of $\delta$-aminolevulinic acid dehydratase ( $\delta$-ALAD). This zinc-containing enzyme catalyzes the second reaction in the heme pathway so inhibition of this enzyme partially explains the anemia observed in lead toxicity [28]. Another prominent mechanism of lead-induced oxidative stress is the effect on antioxidant defense systems of the cells. Lead exhibits a high affinity for sulfhydyl ( $\mathrm{SH}$ ) groups and can interfere with antioxidant activities by inhibiting functional $\mathrm{SH}$ groups in several enzymes such as superoxide dismutase (SOD), catalase (CAT), glutathione peroxidase (GPx), glucose-6-phosphate dehydrogenase (G6PD), and ALAD. It instigates increase yield of free radicals and decreases availability of endogenous anti-oxidant reserves (glutathione, glutathione peroxidase, superoxide dismutase, catalase), involved in scavenging the ROS generated in the lead-exposed individuals. In addition, it impairs activation of enzymes and competitively impedes absorption of trace mineral. It attaches to sulfhydryl proteins, interrupts the synthesis of structural proteins, modifies homeostasis of calcium, heightens lipid peroxidation, decrease saturated fatty acid, and increases cell membrane fatty acid contents [28].

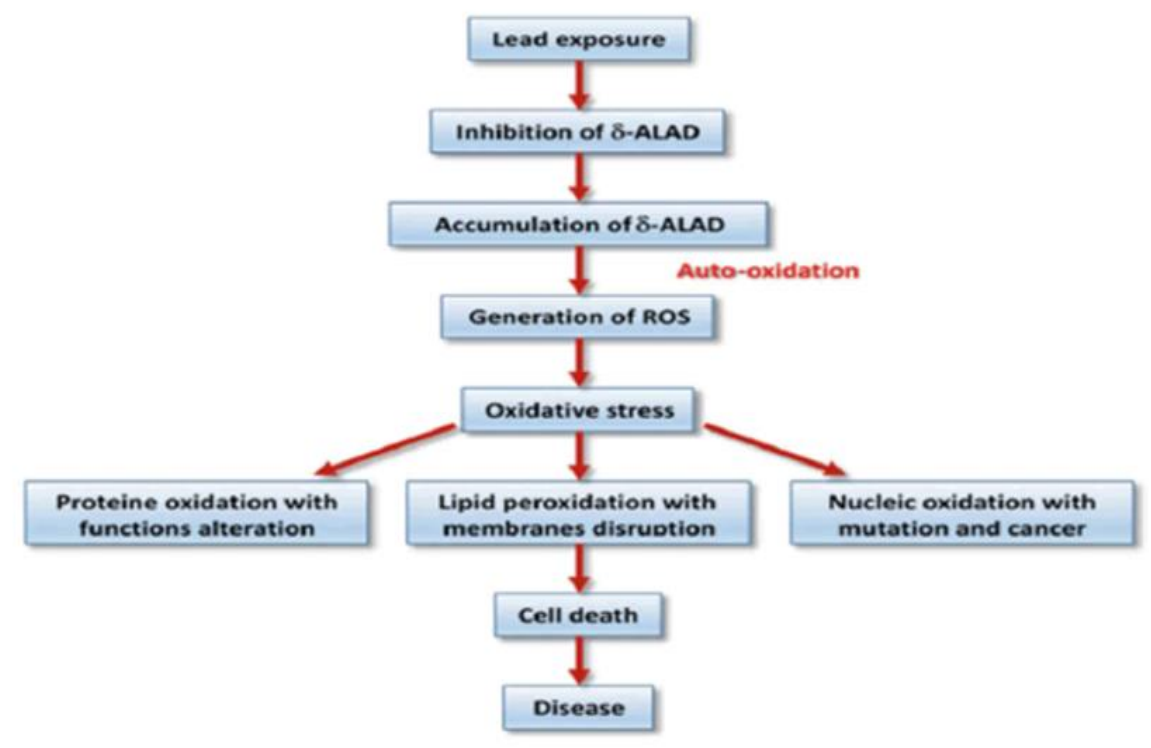

Figure 1 Mechanism for lead-induced oxidative stress and cell death

\section{Biomarkers of lead exposure in humans}

Biomarkers are measurable indicators of events in biological systems caused by exposure to environmental factors. Biomarker objectively measure and evaluate normal biologic processes, pathogenic processes, or pharmacologic responses to a therapeutic intervention. Biomarkers can also be clinically used to screen for, diagnose or monitor the activity of disease and to guide molecularly targeted therapy or assess therapeutic response.

\section{Blood and urine lead levels as biomarkers of lead exposure}

Several literatures have demonstrated the mechanistic relationship between lead $(\mathrm{Pb})$ and the cascade of enzymatic processes involved in heme synthesis. Pb directly inhibits the activity of the cytoplasmic enzyme ð-aminolevulenic acid dehydrogenase (ALA-D), resulting in a negative exponential relatively between ALA-D and blood - $\mathrm{Pb}$. In the past few years, whole blood has been the primary biological fluid used for assessment of lead exposure in humans, both for screening and diagnostic purposes. The blood-lead levels are reflection of recent and past exposure as a result of $\mathrm{Pb}$ mobilization for bone back into blood [29]. Children exposed to lead have been reported to have over $90 \%$ of bone lead converted to blood. In another literature; subjects with excessive exposure to lead from $45-75 \%$ of the lead in blood 
may hence come from bone [29]. Plasma/serum lead (Pb) could likely represent a more relevant index of exposure to distribution of, and health risks associated with lead than does the blood-lead [30].

\section{Hepatorenal indices as biomarkers of lead exposure}

Renal dysfunction ensues predominantly at high levels of lead exposure $(60 \mu \mathrm{g} / \mathrm{dL})$ but damage at lower levels has been stated $(\sim 10 \mu \mathrm{g} / \mathrm{dL})$. Lead-induced renal functional aberration is of two types: Chronic nephropathy and acute nephropathy. Acute nephropathy is characterized primarily by impairment in the functional mechanism of tubular transport, and structurally by the manifestation of degenerative alterations in the tubular epithelium alongside the manifestation of nuclear inclusion bodies, comprising lead protein complexes [31].

Blood-urea nitrogen, uric acid and electrolytes are important biomarkers of renal functioning, which could be considered as suitable prognostic indicator of renal dysfunction majorly attributed to heavy metal exposure or toxicity. In a work to assess biomarkers of renal functioning in commercial automobile mechanics in Benin City, Edo State Nigeria, Adejumo et al. [32] involved 108 males in the ages of 18-60years, 50 of which are controlled subjects (unexposed). From their studies, observed that serum uric acid, urea, chloride bicarbonate and creatinine levels in all the exposed groups were significantly higher $(\mathrm{P}<0.05$ or $\mathrm{P}<0.01)$ compared with non-exposed group, indicating greater levels of renal biomarkers in commercial automobile workers compared with the controls. Thus, the occupationally exposed automobile workers may be at risk of renal disease. It is therefore eminent to proceed further on more broader and specific heavy metal biomonitoring indices in these groups of individuals.

\section{Hematological indices as biomarkers of lead exposure}

One of the initially observed hematological effects of lead poisoning is the basophilic stippling's of erythrocytes which is potential biomarker for detection of lead toxicity. This aggregates as products of degradation of ribonucleic acid [33]. Lead directly affects the hematopoietic system through restraining the synthesis of hemoglobin by inhibiting various key enzymes involved in the heme synthesis pathway. It also reduces the life span of circulating erythrocytes by increasing the fragility of cell membranes. Anemia caused on account of lead poisoning can be of two types: hemolytic anemia, which is associated with acute high-level lead exposure, and frank anemia, which is caused only when the blood lead level is significantly elevated for prolonged periods. Other noticeable hematological changes, associated with lead induced-toxicity include; anemia characterized by anisocytosis and RBC lipo-peroxidation leading to increased RBC fragility; thrombocytopenia and leucopenia [34].

\section{Oxidative stress markers (GSH, SOD, MT) as biomarkers of lead exposure in humans}

Oxidative stress, a process which produces reactive oxygen species (ROS) or reactive nitrogen species (RNS), is an imbalance between the pro-oxidants and antioxidants in the body [35]. Pro-oxidants may be either exogenous or endogenous. The harmful effects of free ROS and RNS are potential biological damage where there is either a disproportionate production of ROS/RNS and/or a deficiency of antioxidants [36].

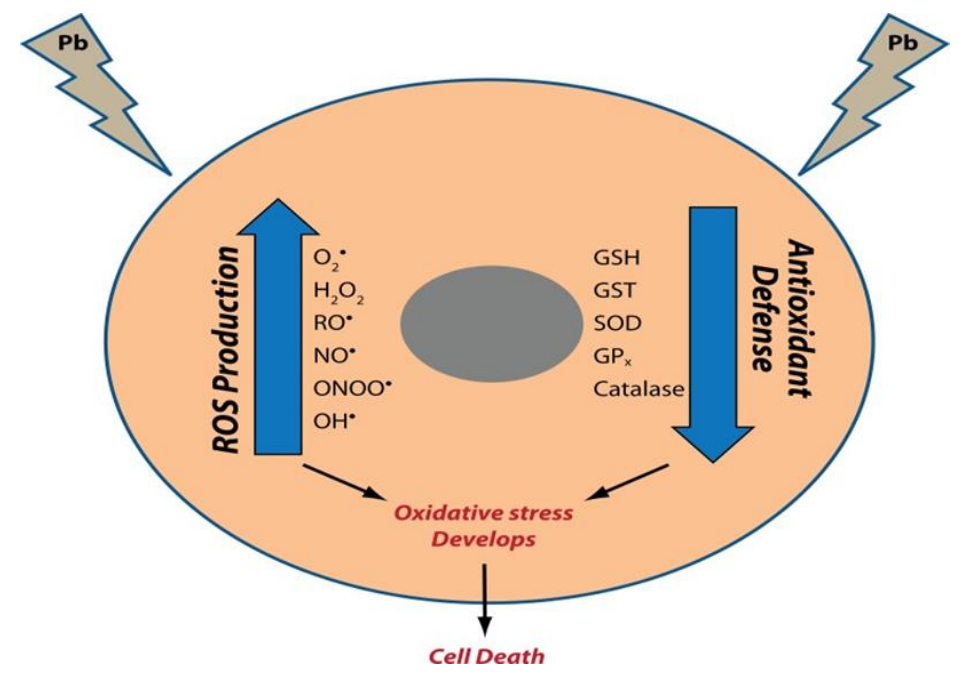

Figure 2 Effects of antioxidants on lead-induced oxidative stress. 
In the study by Jan et al. [37], they investigated the association between blood lead levels and oxidative stress biomarker (MDA), there was a significant increase in the MDA levels $(9.64 \mu \mathrm{mol} / \mathrm{L})$ and blood lead levels in lead-exposed hypertensive subjects $(5.28 \mu \mathrm{g} / \mathrm{dL})$ compared to the control group $(8.23 \mu \mathrm{mol} / \mathrm{L}$ and $4.41 \mu \mathrm{g} / \mathrm{dL})$. Also, a positive correlation between blood lead levels and antioxidant biomarkers (GPx, CAT, SOD and GSH) was reported. With the antioxidants levels depleted in subjects with lead-induced hypertension compared to subjects with normotension [37]. These associations have been reported in both occupational workers and population with low exposure to environmental lead. Lipid peroxidation is a well-established mechanism of cellular injury and is used as an indicator of oxidative stress in cells and tissues. Therefore, since MDA is widely adopted as an indicator of lipid peroxidation. The findings above also support the evidence of lead-induced ROS generation which represents oxidative stress [38].

\section{Diagnosis of lead toxicity}

In order to prevent lead poisoning and toxicity, proper diagnosis is a primary and rather important issue. In order to make a proper diagnosis, an inquiry about the possible routes of exposure e is a must [39]. The inquiry should include medical history and determination of clinical signs. The involvement of proper staff, i.e. clinical toxicologists and medical specialists, can help in establishing proper diagnosis and treatment. Basophilic stripping is an important sign of lead poisoning. This stripping makes dots in red blood cells visible through the microscope [40]. Thus an examination of blood film for such signs could be effective in detecting lead poisoning. Lead poisoning is associated with iron deficiency anaemia. Lead poisoning can also be evaluated by measuring erythrocyte protoporphyrin (EP) in blood samples [40]. EP is known to increase when the amount of lead in the blood is high, with a delay of a few weeks [41]. However, the EP level alone is not sensitive enough to identify elevated blood lead levels below approximately $35 \mu \mathrm{g} / \mathrm{dL}$ [40]. Due to this higher threshold for detection and the fact that EP levels also increase in iron deficiency, the use of this method for detecting lead exposure has decreased. Blood lead levels are an indicator mainly of recent or current lead exposure, not of the total body burden. The measurement of blood lead level does not give the actual account of lead stored in the body, it is just an indicator of recent lead exposure. Whole body lead can be measured in bones noninvasively by X-ray fluorescence; this may be the best measure of cumulative exposure and total body burden [41]. X-rays may also reveal leadcontaining foreign materials such as paint chips in the gastrointestinal tract $[31,41]$.

\section{Prevention and treatment}

Lead poisoning causes severe effects and is a matter of serious concern, yet importantly, it is preventable. The best approach is to avoid exposure to lead [42]. It is recommended to frequently wash the children's hands and also to increase their intake of calcium and iron. It is also recommended to discourage children from putting their hands, which can be contaminated, in their mouth habitually, thus increasing the chances of getting poisoned by lead. Vacuuming frequently and eliminating the use and or presence of lead containing objects like blinds and jewellery in the house can also help to prevent exposures. House pipes containing lead or plumbing solder fitted in old houses should be replaced to avoid lead contamination through drinking water. It is believed that hot water contains higher lead levels than does cold water, so it is recommended that for household uses cold water should be preferred to hot water [43]. The treatment for lead poisoning consists of dimercaprol and succimer [44]. Due to the persistent findings on cognitive deficits caused by lead poisoning particularly in children, widespread reduction of exposure should be mandatory. Lead poisoning is generally treated by using chelating salt disodium calcium edentate, which is the calcium chelate of the disodium salt of ethylene-diamine-tetracetic acid (EDTA). Such chelating agents have a great affinity to the removing agent. The chelating agent for lead has a greater affinity to lead than calcium and so the lead chelate is formed by exchange. This is then excreted in urine, leaving behind harmless calcium. Blood lead levels were shown to be lowered by treatment with succimer used as chelation therapy in children exposed to lead to improve their neuropsychological development. And yet, though succimer was observed to help in reducing blood lead levels, it failed in improving the scores of cognition tests [45]. There is a number of antioxidants which are believed to act against toxicity of chemicals like lead and its related compounds. A new technique called nano-encapsulation of antioxidants may provide improved biodistribution and bioavailability of poorly soluble therapeutics through solubilisation [46]. Encapsulation of curcumin in a pluronic block copolymer demonstrated a slow and sustained release of curcumin and showed anticancer activity comparable with free curcumin [42]. These new techniques may hold a promise for treating a number of human diseases. In a very recent study, it was observed that puerarin promoted Akt and GSK-3 $\beta$ phosphorylation in PC12 cells exposed to lead acetate. The authors of the study concluded that puerarin as a phytoestrogen might be an attractive agent for prevention and treatment of chronic diseases related to lead neurotoxicity. In another recent finding betacarotene was observed to have an antioxidant action and exert some beneficial effects in lead poisoning, independent of chelation [47]. The authors also found significantly decreased homocysteine levels due to administration of betacarotene in lead exposed workers. Recently a study on a group of workers occupationally exposed to lead found that those treated with $\mathrm{N}$-acetylcysteine (NAC) showed a significant reduction in their blood lead levels. In addition, all 
groups receiving NAC were shown to have significantly elevated activity of glutamate dehydrogenase. It was further reported that treatment with NAC normalised the level of homocysteine and decreased oxidative stress. It was thus concluded that NAC could be recommended as an alternative therapy for chronic lead toxicity in humans [48].

\section{Conclusion}

This review had successfully discussed the effects of lead on the environment and living organisms, mainly human beings. Stringent legislation, guidelines and detection of this heavy metal should be enforced since failure to control its exposure will lead to severe complications in the future because of the adverse effects imposed by the metal.

\section{Compliance with ethical standards}

\section{Acknowledgments}

The authors acknowledge all authors of scientific works that has been referenced in this write-up.

\section{Disclosure of conflict of interest}

The authors state that they have no conflict of interest to disclose.

\section{References}

[1] Jarup L. Hazards of heavy metal contamination. Br Med Bull. 2003; 68(1): 167-182.

[2] Monisha J, Tenzin T, Naresh A, Blessy BM, Krishnamurthy NB. Toxicity, mechanism and health effects of some heavy metals. Interdiscip Toxicol. 2014; 7(2): 60-72.

[3] Jaishankar M, Mathew BB, Shah MS, Gowda KRS. Biosorption of few heavy metal ions using agricultural wastes. Journal of Environment Pollution and Human Health. 2014; 2(1): 1-6.

[4] Nagajyoti PC, Lee KD,Sreekanth TVM. Heavy metals, occurrence and toxicity for plants: a review. Environ Chem Lett. 2010; 8(3): 199-216.

[5] Mahaff ey KR. Environmental lead toxicity: nutrition as a component of intervention. Environ Health Perspect. 1990; 89: 75-78.

[6] Ab Latif W, Anjum A, Jawed AU. Lead toxicity: a review. Interdiscip Toxicol. 2015; 8(2): 55-64.

[7] National Research Council (NRC). Biologic markers in reproductive toxicology. Washington D.C. National Academy Press. 1989.

[8] Jacobs DE, Chickner RP, Zhon JY et al. The prevalence of lead-based paint hazards in U.S. housing. Environmental Health Perspective. 2002; 110: 599-606.

[9] Farfel MR, Chisolm JJ. An evaluation of experimental practices for abatement of residential lead-based paint. Report on a pilot project. Environmental Research. 1991; 55:199-212.

[10] Lanpher BP, Matte TD, Rogers J et al. The contribution of lead contaminated house dust and residential soil to children's blood lead levels. A pooled analysis of 12 epidemiological studies. Environmental Research. 1998; 79: 51-68.

[11] Aliyu HS, Musa A, Cyril O. Trace and heavy metals status in selected staple foods and associated health risk in artisanal and small scale gold mining vicinity in Kuchiko-Hausa, Gurara LGA, Niger state, Nigeria. ATBU Journal of Science, Technology and Education. 2020; 8(4): 231-241.

[12] Woolf AD, Goldman R, Bellinger DC. Update on clinical management of childhood lead poisoning. Pediatric Clinic North America. 2007; 54: 271-294.

[13] Needleman H. Lead poisoning. Annu Rev.Med. 2004; 55: 209-222.

[14] Patrick L. Lead toxicity; a review of the literature. Part I. Exposure, evaluation and treatment. Altern Med Rev. 2006; 11: 2-22.

[15] Rubin R, Strayer DS. ed. Environmental and nutritional pathology. Rubins pathology; Clinicopathologic Foundations of Medicine, 5th Ed, Lippincot Williams \& Wilkins. 2008. 
[16] Sokol RZ, Berman N. The effect of age of exposure on lead-induced testicular toxicity. Toxicology. 1991; 69: 269278.

[17] Kosnett MJ. Lead. In Brent, J. Critical Care Toxicology: Diagnosis and Management of the Critically Poisoned Patient. Gulf Professional Publishing. 2005.

[18] Bellinger DC.Lead. Pediatrics. 2004; 113(4 Suppl): 1016-1022.

[19] Mycyk M, Hryhorcu D, Amitai Y. "Lead" In Erickson TB, Ahrens WR, Aks S, Ling L. Paediatric Toxicology: Diagnostic and Management of the Poisoned Child. Mcgraw Hill Professional. 2005.

[20] Dart RC, Hurlbut KM, Boyer-Hassen LV. Lead. In Dart, RC. Medical Toxicology, (3rd Ed.), Lippincot Williams and Wilkins. 2004.

[21] Patrick L. Lead toxicity, a review of the literature. Part 1: Exposure, evaluation, and treatment. Altern Med Rev. 2006; 11: 2-22.

[22] Pearce JMS. Burton's line in lead poisoning. Eur Neurol. 2007; 57: 118-119.

[23] Merill JC, Morton JJP, Soileau SD. Metals. In Hayes, A.W. Principles and methods of toxicology (5th ed.) CRC Press. 2017.

[24] Henretig FM. Lead. In: Golgfrank, LR. Goldfrank's Toxicoliogic Emergencies (8th Ed.) McGraw Hill Professional. 2006.

[25] Brunton LL, Goodman LS, Blumenthal D, Buxton I, Parker KL. Goodman and Gillmans, Manual of Pharmocology and Theraupetics. Mcgraw Hill Professional. 2007.

[26] Centers for Disease Control and Prevention (CDC). Low Level Lead Exposure. 2012.

[27] Harms Children: A Renewed Call for Primary Prevention. Retrieved 30th March 2021.

[28] Bergeson LL. The proposed lead NAAQS: Is consideration of cost in the clean air act's future?. Environmental Quality Management. 2008; 18: 79-84.

[29] Wiencke JK, Kelsey KT, Varkonyi A, et al. Correlation of DNA-adducts in blood mononuclear cells with tobacco carcinogen-induced damage in human lung. Cancer Res. 1995; 55: 4910-4914.

[30] Wakefield J. The lead effect. Environ. Health Perspec. 2002; 110: A574-A580.

[31] Vineis P, Husgafvel-Pursiainen K. Air pollution and cancer: biomarker studies in human populations. Carcinogenesis. 2005; 26: 1846-1855.

[32] Grant LD. Lead and compounds. In Lippmann, M. Enviromental toxico kinetics, human exposure and their health effects, (3rd Ed), Willey - Interscience. 2009.

[33] Adejumo B, Awelogun K, Uchuno G, Emmanuel A, Dimkpa U, Omosor K, Abdulrahman O. Assessment of renal biomarkers of renal function in commercial automobile workers in Benin City, Edo State, Nigeria. Open Journal of Nephrology. 2018; 8: 18-28.

[34] Patrick LF. Lead toxicity; a review of the literature. Physio. Med Rev. 2009; 1(2): 12-17.

[35] Vineis P, Husgafvel-Pursiainen K. Air pollution and cancer: biomarker studies in human populations. Carcinogenesis. 2005; 26: 1846-1855.

[36] Rachel SK, Paolo V. Biomarkers of susceptibility to chemical carcinogens: the example of nonHodgkin lymphomas. British Medical Bulletin. 2014; 3(1): 89-100.

[37] Centre for Disease Control and Prevention (CDC). Folk Medicine.2014.

[38] Jan AT, Azam M, Siddiqui K, Ali A, Choi I, Haq QMR. Heavy metals and human health: Mechanistic insight into toxicity and counter defense system of antioxidants. Intl. Journal of Molecular Science. 2015; 16: 29592-29630.

[39] Tang D, Warburton D, Tannenbaum SR, et al. Molecular and genetic damage from environmental tobacco smoke in young children. Cancer Epi Bio Prev. 1999; 8: 427-431.

[40] Nevin R. Understanding international crime trends: the legacy of preschool lead exposure. Environ Res. 2007; 104: 315-336.

[41] He Y, von Lampe K, Wood L, Kurti M. Investigation of lead and cadmium in counterfeit cigarettes seized in the United States. Food Chem Toxicol. 2015; 81: 40-45. 
[42] Kosnett MJ. Heavy metal Intoxication and chelators. In Katzung BG. Basic and clinical Pharmocology. McGraw Hill Professional. 2007.

[43] Rossi E. Low level environmental lead exposure - A continuing challenge. Clin Biochem Rev. 2008; $29: 63-70$.

[44] Baselt RC. Disposition of toxic drugs and chemicals in man (8th Ed.), Biomedical Publications. 2008 ; 823-826.

[45] Park SK, O’Neill MS, Vokonas PS, Sparrow D, Wright RO, Coull B, Nie H, Hu H, Schwartz J. Air pollution and heart rate variability: Effect modification by chronic lead exposure. Epidemiology. 2018; 19: 111-120.

[46] Rogan WJ, Dietrich KN, Ware JH, Dockery DW, Salganik M, Radcliff EJ, Jones RL, Ragan NB, Chisolm JJ Jr, Rhoads GG. The effect of chelation therapy with succimer on neuropsychological development in children exposed to lead. N Engl J Med. 2001; 344(19): 1421-1426.

[47] Flora SJ, Mittal M, Mehta A. Heavy metal induced oxidative stress \& it's possible reversal by chelation therapy. Indian J Med Res. 2008; 128: 501-523.

[48] Dobrakowski M, Kasperczyk J, Romuk E, Prokopowicz A, Birkner E. The influence of beta-carotene on homocysteine level and oxidative stress in lead-exposed workers. Med Pr. 2014; 65: 309-316.

[49] Kasperczyk S, Dobrakowski M, Kasperczyk A, Romuk E, Rykaczewska-Czerwińska M, Pawlas N, Birkner E. Effect of N-acetylcysteine administration on homocysteine level, oxidative damage to proteins, and levels of iron (Fe) and Fe-related proteins in lead-exposed workers. Toxicol Ind Health. 2015; 19: 34-39 